\title{
Review Article \\ The Relationship between Type 2 Diabetes Mellitus and Related Thyroid Diseases
}

\author{
Chaoxun Wang \\ Department of Endocrinology, Shanghai Pudong Hospital, Fudan University Pudong Medical Center, 2800 Gongwei Road, \\ Huinan Town, Pudong, Shanghai 201399, China
}

Correspondence should be addressed to Chaoxun Wang; xunshdonger@hotmail.com

Received 20 January 2013; Accepted 15 March 2013

Academic Editor: Åke Lernmark

Copyright (C) 2013 Chaoxun Wang. This is an open access article distributed under the Creative Commons Attribution License, which permits unrestricted use, distribution, and reproduction in any medium, provided the original work is properly cited.

Type 2 diabetes mellitus (T2DM) has an intersecting underlying pathology with thyroid dysfunction. The literature is punctuated with evidence indicating a contribution of abnormalities of thyroid hormones to type $2 \mathrm{DM}$. The most probable mechanism leading to T2DM in thyroid dysfunction could be attributed to perturbed genetic expression of a constellation of genes along with physiological aberrations leading to impaired glucose utilization and disposal in muscles, overproduction of hepatic glucose output, and enhanced absorption of splanchnic glucose. These factors contribute to insulin resistance. Insulin resistance is also associated with thyroid dysfunction. Hyper- and hypothyroidism have been associated with insulin resistance which has been reported to be the major cause of impaired glucose metabolism in T2DM. The state-of-art evidence suggests a pivotal role of insulin resistance in underlining the relation between T2DM and thyroid dysfunction. A plethora of preclinical, molecular, and clinical studies have evidenced an undeniable role of thyroid malfunctioning as a comorbid disorder of T2DM. It has been investigated that specifically designed thyroid hormone analogues can be looked upon as the potential therapeutic strategies to alleviate diabetes, obesity, and atherosclerosis. These molecules are in final stages of preclinical and clinical evaluation and may pave the way to unveil a distinct class of drugs to treat metabolic disorders.

\section{Introduction}

The role of hyperthyroidism in diabetes was investigated in 1927, by Coller and Huggins proving the association of hyperthyroidism and worsening of diabetes. It was shown that surgical removal of parts of thyroid gland had an ameliorative effect on the restoration of glucose tolerance in hyperthyroid patients suffering from coexisting diabetes [1].

There is a deep underlying relation between diabetes mellitus and thyroid dysfunction [2]. A plethora of studies have evidenced an array of complex intertwining biochemical, genetic, and hormonal malfunctions mirroring this pathophysiological association $[2,3] .5^{\prime}$ adenosine monophosphateactivated protein kinase (AMPK) is a central target for modulation of insulin sensitivity and feedback of thyroid hormones associated with appetite and energy expenditure [3]. Hypothyroidism (Hashimoto's thyroiditis) or thyroid over activity (Graves' disease) has been investigated to be associated with diabetes mellitus. A meta-analysis reported a frequency of
$11 \%$ in thyroid dysfunction in the patients of diabetes mellitus [4]. Autoimmunity has been implicated to be the major cause of thyroid-dysfunction associated diabetes mellitus [5-7].

Unmanaged pro diabetes, both type 1 and type 2, may induce a "low T3 state" characterized by low serum total and free T3 levels, increase in reverse T3 (rT3) but near normal serum T4 and TSH concentrations [8]. The relation between T2DM and thyroid dysfunction has been a less explored arena which may behold answers to various facts of metabolic syndrome including atherosclerosis, hypertension, and related cardiovascular disorders.

T2DM owes its pathological origin to inappropriate secretion of insulin, due to defective islet cell function or beta cell mass. Continuous consumption of calories-rich meals, junk food and sedentary lifestyle have culminated into an epidemic of diabetes projected to afflict around 300 million people across the globe by 2020 [9]. Defective insulin secretion leads to various metabolic aberrations in T2DM, spanning from hyperglycemia due to defective insulin-stimulated glucose 
uptake and upregulated hepatic glucose production, along with dyslipidaemia, which includes impaired homeostasis of fatty acids, triglycerides, and lipoproteins [10].

\section{Epidemiology}

Thyroid dysfunction is a common endocrine disorder with variable prevalence. Wickham survey reveals that a prevalence of thyroid dysfunction in male adults in England was $6.6 \%$ [11]. According to Colorado prevalence study, 9.5\% of participants were found to have elevated thyroid-stimulating hormone (TSH), while $2.2 \%$ had a low TSH. According to the National Health and Nutrition Examination Survey (NHANES III Study), hypothyroidism and hyperthyroidism were reported in $4.6 \%$ and $1.3 \%$ of the total participants [12], respectively. The prevalence of thyroid dysfunction is advancing with age all over the world, and frequency of prevalence was higher in women than men. The prevalence of subclinical hypothyroidism is reported to be about 4 to 8.5 percent, and may be as high as 20 percent in women older than 60 years. The prevalence of subclinical hyperthyroidism is reported to be approximately $2 \%$.

The prevalence of thyroid disorder in diabetic population was reported to be $13.4 \%$ with higher prevalence $(31.4 \%)$ in female T2DM patients as compared to $(6.9 \%)$ in male T2DM patients [13]. The prevalence of thyroid dysfunction in T2DM patients was reported to be $12.3 \%$ in Greece and $16 \%$ in Saudi Arabia by Akbar et al. [14]. Considerably, T2DM patients were more prone to thyroid disorders.

\section{Peripheral Effects of Thyroid Hormones on Insulin Secretion and Sensitivity}

Thyroid hormones directly control insulin secretion. In hypothyroidism, there is a reduction in glucose-induced insulin secretion by beta cells, and the response of beta cells to glucose or catecholamine is increased in hyperthyroidism due to increased beta cell mass. Moreover, insulin clearance is increased in thyrotoxicosis $[15,16]$.

3.1. Thyrotoxicosis. Increased glucose output from liver is the pivotal reason for the induction of hyperinsulinaemia, induction of glucose intolerance, and development of peripheral insulin resistance [17]. Glucose tolerance in thyrotoxicosis is caused by elevated hepatic glucose output along with upregulated glycogenolysis [2]. This phenomenon is responsible for worsening of subclinical diabetes and exaggeration of hyperglycaemia in T2DM. Thyrotoxicosis may lead to ketoacidosis also due to elevated lipolytic actions and increased hepatic $\beta$ oxidation $[18,19]$. This phenomenon has been shown in Figure 1.

3.2. Hypothyroidism. Reduced glucose absorption from gastrointestinal tract accompanied by prolonged peripheral glucose accumulation, gluconeogenesis, diminished hepatic glucose output and reduced disposal of glucose are hallmarks of hypothyroidism [20]. In overt or subclinical hypothyroidism,

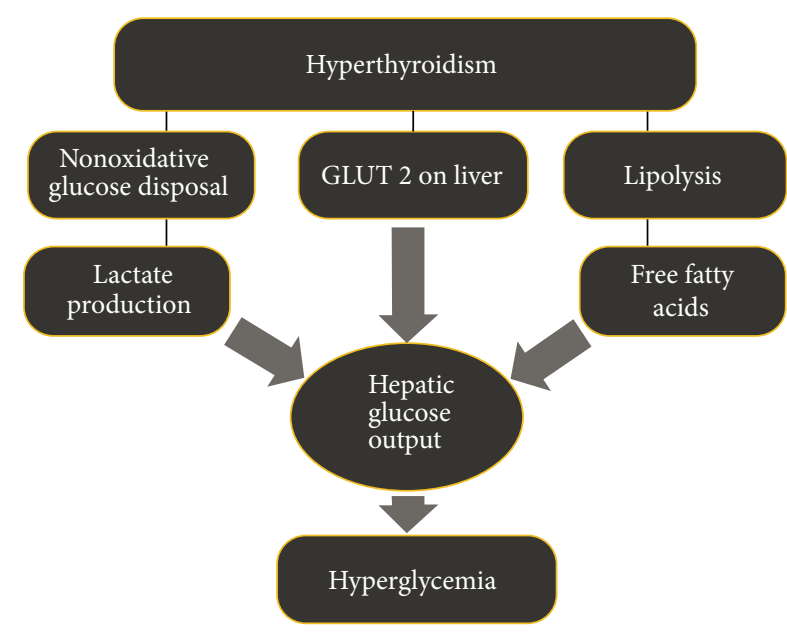

FIGURE 1: The relation between hyperthyroidism and hyperglycemia via lipid metabolism oxidative stress and hepatic dysfunction.

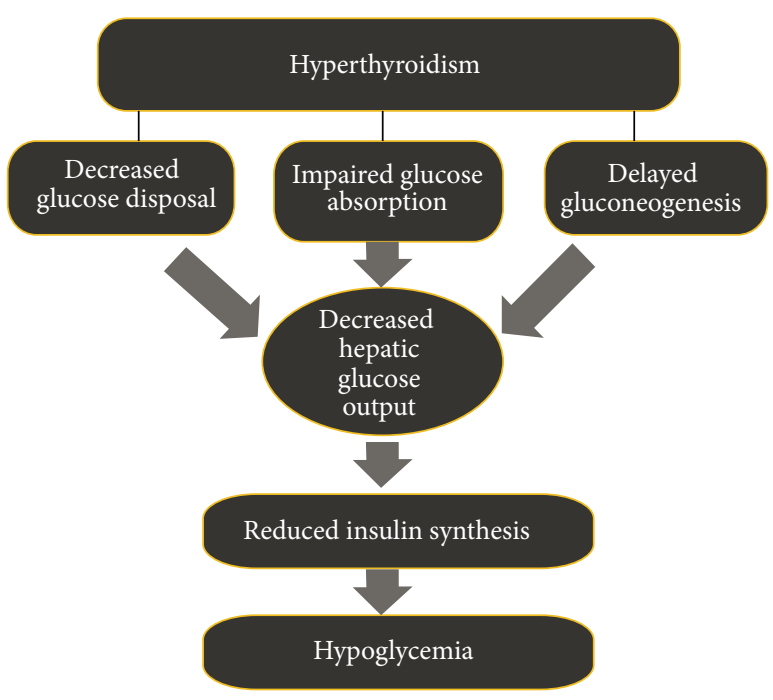

FIGURE 2: The relation between hypothyroidism and hypoglycemia mediated by reduced insulin synthesis and impaired hepatic glucose output.

insulin resistance leads to glucose-stimulated insulin secretion [2]. In subclinical hypothyroidism, diminished rate of insulin stimulated glucose transport rate caused by perturbed expression of glucose transporter type 2 gene (GLUT 2) translocation may lead to insulin resistance. Moreover, due to reduced renal clearance of insulin in hypothyroid conditions, physiological requirements of insulin were diminished. Anorectic conditions in hypothyroidism may also contribute to reduced insulin in this state. An enhanced dose of insulin is required to ameliorate hypothyroidism, but the therapy warrants caution for adrenal or pituitary failure [21]. This phenomenon has been shown in Figure 2. 


\section{Relation between the Pathological Features Exhibited in Hyperthyroidism and T2DM: Role of Insulin Resistance and Other Factors}

The pathological features of T2DM include increased intestinal glucose absorption, reduced insulin secretion, and change in the $\beta$-cell mass [22]. Further, symptoms also include increased insulin degradation [23], increased glucagon secretion [24], increased hepatic glucose production [24], enhanced catecholamines, and insulin resistance [25]. These factors have been investigated to be an integral part of hyperthyroidism as well [26]. Hence, an intersection of pathological basis occurs which gives us cue to an array of physiological aberrations which are common in hyperthyroidism and T2DM. Among the above-mentioned symptomatology, insulin resistance has been the most important facet connecting thyroid dysfunction and T2DM. Insulin resistance is a condition which occurs in both hypothyroidism and hyperthyroidism [27].

Insulin resistance in the muscles and liver is a characteristic feature of T2DM. An undisturbed glucose homeostasis and intact insulin secretary response and unperturbed sensitivity of the tissues to insulin are essential to maintain normal blood glucose levels [28-31].

Glucose disposal is mediated by the conjoint effect of insulin and hyperglycemia to modulate three basic phenomenon. Firstly, diminution of endogeneous (hepatic) glucose production. Secondarily, enhanced uptake of glucose (hepatic and splanchnic). Thirdly, upregulation of glucose by peripheral tissues (skeletal muscles). Glucose uptake into muscles is modulated by glycolysis and glycogen synthesis. Hepatic insulin resistance is characterized by glucose overproduction inspite of fasting hyperinsulinemia, and enhanced rate of hepatic glucose output was the pivotal modulator of increased fasting plasma glucose (FPG) concentration in T2DM subjects [24]. In insulin resistance in the postabsorptive state, muscle glucose is upregulated but the efficiency of uptake is reduced. In the wake of such conditions, reduced glucose uptake into the muscles and enhanced hepatic glucose output lead to worsening of glucose metabolism.

The term harmonious quartet is used to address the core pathology of insulin resistance [24]. Deregulated glucose disposal and metabolism in adipocytes, muscles, and liver, along with impaired insulin secretion by the pancreatic beta cells, constitute the four major organ system abnormalities which play a definitive role in the pathogenesis of T2DM. It is worth considering that insulin resistance has been a proven condition in hyperthyroidism as well as hypothyroidism. Insulin resistance also leads to impaired lipid metabolism according to recent findings [32]. Hence, it appears that insulin resistance is the possible link between T2DM and thyroid dysfunction.

Insulin resistance and $\beta$ cell function are inversely correlated with thyroid stimulating hormone which may be explained by insulin-antagonistic effects of thyroid hormones along with an increase in TSH. The higher serum TSH usually corresponds to lower thyroid hormones via negative feedback mechanism. As TSH increased, thyroid hormones decreased and insulin antagonistic effects are weakened. These observations demonstrate that insulin imbalance is closely associated with thyroid dysfunction and the phenomenon id mediated via $\beta$ cell dysfunction [33].

4.1. Association of Insulin Resistance in Hyperthyroidism and Subclinical Hyperthyroidism. Hyperthyroidism has been associated with insulin resistance which has been linked with elevated glucose turnover, increased intestinal glucose absorption, elevated hepatic glucose output, increased free fatty acid concentrations, increased fasting and or postprandial insulin an proinsulin levels, and increased peripheral glucose transport accompanied by glucose utilization [27, 34]. T2DM patients with thyroid dysfunction have been proven to be more susceptible to ketosis [35] and ketogenesis [36]. Insulin resistance has been shown to be associated with subclinical hypothyroidism, which is in turn linked to impaired lipid balance and risk of development of metabolic syndrome [37-39].

4.1.1. Role of Liver. In hyperthyroidism, endogenous glucose production is elevated and reduces hepatic insulin sensitivity in humans [40] due to glycogenesis and glycogenolysis. The role of hypothalamus mediated sympathetic action in liver has been proposed [41] along with increased expression of GLUT 2 transporters in liver which ultimately lead to elevation in plasma free fatty acid $[42,43]$.

4.1.2. Role of Muscles. There is marked increase in the skeletal glucose utilization in hyperthyroid state [34]. Increased glucose utilization has been reported to be mediated by insulin stimulated glucose oxidation rates [44-46]. Under such conditions, reduced glyco genesis has been reported due to insulin stimulated nonoxidative glucose disposal, which is accompanied by redirection of intracellular glucose towards glycolysis and lactate formation [27]. The transport of lactate from periphery to liver leads to enhanced production of glucose via Cori's cycle. Hyperthyroidism has also been associated with enhanced insulin sensitivity [47]. Increased peripheral insulin resistance has been coupled with elevated expression of bioactive inflammatory mediators including adipokines (IL-6 and TNF-alpha) [16] which lead to insulin resistance.

4.1.3. Role of Fat Tissues. Haluzik et al. summarized that rate of local lipolysis in the abdominal subcutaneous adipose tissue was a result of modulation of norepinephrine (NE) levels and adrenergic postreceptor signaling by thyroid hormones [48]. Other studies reported that thyroid hormones are necessary for the mobilization of the tissue lipids especially brown adipose tissues (BATs) which are the fuel for the production of heat [49]. Hypothyroidism and decreased thyroid hormone level are responsible for decreased thermogenesis in BAT. S14 and lipogenesis are important factors for thermogenesis mediated by thyroid hormone [50].

4.2. Association of Insulin Resistance in Hypothyroidism and Subclinical Hypothyroidism. Insulin resistance has been shown to be caused in hypothyroidism in various in vitro and 
preclinical studies [51-53] where it was found that peripheral muscles became less responsive in hypothyroid conditions. A possible role of dysregulated metabolism of leptin has been implicated for such pathology [53]. A direct relation between hypothyroidism and insulin resistance has been demonstrated by various authors $[15,54-56]$.

Subclinical hypothyroidism has been reported to be associated with insulin resistance [55, 57, 58]. However, conflicting findings have also been reported by other workers $[59,60]$, indicating the need of further investigations in this domain.

\section{Genetic Causes of T2DM and Thyroid Dysfunction: The Possible Intersection}

5.1. Effect of Thyroid Hormones on the Liver: The Role of Genes. Various genes have been identified which are identified with gluconeogenesis, glycogen metabolism, and insulin signaling. These include glucose 6 phosphate, protein kinase B (Akt2), $\beta_{2}$ adrenergic receptor, inhibitory $G$ protein (Gi), phosphoenolpyruvate kinase (PEPCK) [25], pyruvate carboxylase (PC), GLUT 2 [42, 64], malic enzyme [65], and carbohydrate response element binding protein (ChREBP) [66]. A raised hepatic expression of GLUT 2 in hyperthyroid rats was observed as compared to hypothyroid rats [64].

Transcription of various enzymes involved in lipid metabolism has been reported to increase in hyperinsulinemic or insulin-resistant mice $[2,67]$. Transcriptional activation of malic acid has proven to be involved in fatty acid synthesis [68].

5.2. Effect of Thyroid Hormones on the Skeletal Muscle. The various genes which influence the interaction of thyroid hormone and skeletal muscles include GLUT1, GLUT4 [64], $\beta_{2}$ adrenergic receptors [69], phosphoglycerate kinase (PGK) [70], PPAR gamma coactivator-1 alpha (PGC-1 alpha) [71], and mitochondrial uncoupling protein [72]. Amongst the various genes identified, GLUT-4 and UCP-3 have been studied in detail. In the skeletal muscles, GLUT 4 has been proven to be mediated by the influence of $\mathrm{T} 3$, and it can elevate basal and insulin mediated transport of glucose [64].

Mitochondrial uncoupling protein 3 (UCP 3) is a recently identified gene and has been unveiled to be associated with glucose metabolism and decreased fatty acid oxidation [73]. It has also been reported to play a pivotal role in the downregulated activation of Akt/PKB and $5^{\prime}$ adenosine monophosphate-activated protein kinase signaling $[2,73]$. The role of T2 has also been explored and it has been proven that it is associated with sarcolemmal GLUT-4. Phosphofructokinase and glycolytic enzymes have been associated with the T2mediated GLUT 4 activity [74]. A number of genes have been associated with peripheral glucose metabolism [2].

Autoimmune causes are reported to be responsible for the genetic dysfunction in the diabetic patient suffering from thyroid related disorders. However, these findings advocate an immense clinical evidence to support association between T1DM (Type 1 diabetes mellitus) and autoimmune thyroid dysfunction (AITD) [75, 76]. Arrays of genes involved in metabolism of glucose are modulated by active thyroid hormone $\mathrm{T} 3$ by binding to the thyroid hormone receptors. These receptors are derived from $\mathrm{TR} \alpha 1, \mathrm{TR} \beta 1, \mathrm{TR} \beta 2$, and $\mathrm{TR} \beta 3$. These are four major T3 binding isoforms [77]. TR $\alpha 1$ is hypothesized to regulate the metabolic effects of thyroid hormone. TR $\beta 1$ and TR $\beta 2$ are related with maintenance of hypothalamic-pituitary-thyroid axis and keeping the euthyroid state [78].

It has been investigated that 3,5,3-triiodothyronine is derived from $\mathrm{T} 4$. It can be activated via removing an iodine atom from the phenolic ring by the iodothyronine deiodinases type 1 (D1) and type 2 (D2). Type 3 deiodinase (D3) inactivates thyroid hormone by removing an iodine atom from the tyrosyl ring. The deiodinases are expressed in various tissues, and their expression levels vary enormously during development and are regulated by thyroid hormone status. Type deiodinase (D1) is expressed in liver, while type 2 deiodinase (D2) is expressed in adipose tissue and skeletal muscle. They are involved in regulation of bioavailability of $\mathrm{T} 3$ and hence, the response to insulin. Elevated concentrations of T3 are associated novel missense variant (Thr92Ala). This phenomenon is closely associated with insulin resistance. It is also associated with a surge in glucose turnover accompanied by an upregulation of insulin-mediated glucose disposal in skeletal muscle and adipose tissue.

This phenomenon mediated via positive regulation of insulin sensitive GLUT-4 transcription $[78,79]$ showed that there were profound genomic effects of T3 on hepatic glucose metabolism. TR expressed in the hepatocyte and stimulation of T3-sensitive neurons in the hypothalamus-modulated hepatic glucose production via sympathetic projections to the liver are mediated by circulating glucoregulatory hormones [79]. Recent findings have elucidated polymorphism of deiodinase type 2 (DIO2) gene, Thr92Ala, which suggest homozygosity for this polymorphism which in turn is responsible for enhanced risk of T2DM [80].

A separate meta-analysis indicated that intracellular triiodothyronine (T3) is responsible for aberrations in insulin sensitivity [4]. It has also been reported that polymorphism of Thr92Ala leads to a lower activity of type 2 deiodinase which in turn is associated with insulin resistance. The D2 gene has a peculiar transcriptional and posttranslational regulation. It is a potential modulator of insulin action in skeletal muscle and adipose tissue through the regulation of the GLUT-4 gene transcription [81].

Investigations using skeletal muscles in hypothyroid and euthyroid humans have revealed a discernable influence on the downregulated expression of glucose transporter 5 (GLUT 5) but not GLUT 4 [57, 82]. Glucose oxidation and glycogen synthesis are reduced in hypothyroidism [21]. Simultaneous increase in the insulin sensitivity occurs when the levels of thyroid hormone were increased. This phenomenon is governed by intracellular generation of T3 as polymorphisms of DIO2 with reduced $\mathrm{T} 3$ generation and also contributes to insulin resistance [80]. In hyperthyroidism, the expression of GLUT 2 is increased as compared to euthyroid state [16]. In such conditions, perturbations in lipid metabolism further link $\mathrm{TH}$ to insulin resistance [16]. Thyroid hormone causes elevation in the plasma fatty acid 


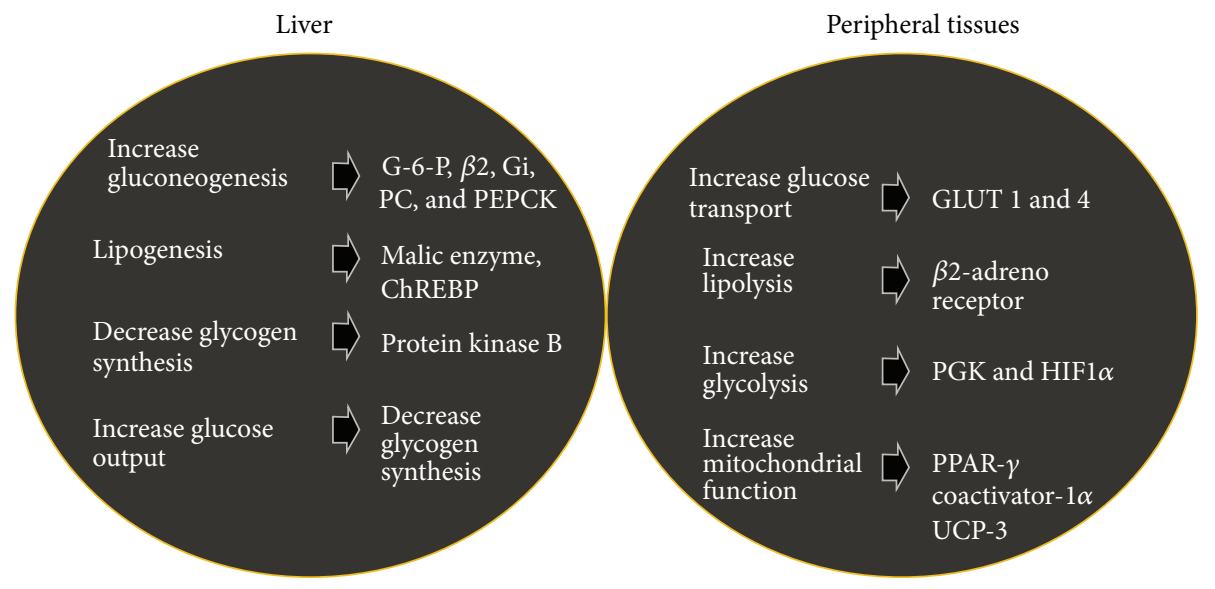

FIGURE 3: : Effect of thyroid hormones on the liver and peripheral tissues.

levels in hyperthyroid conditions but not in hypothyroid conditions. Low intracellular fatty acid levels are associated with hepatic insulin sensitivity via modulation of cellular insulin uptake or lipid oxidation [83]. Fatty acid uptake mediated by $\mathrm{TH}$ is a tissue-specific phenomenon and is upregulated in both hypo, and hyperthyroidism [79].

Thyrotoxicosis leads to enhanced lipid peroxidation whereas hypothyroidism causes diminished glucose oxidation. LDL clearance leads to lowered cholesterol and triglyceride levels. $\mathrm{TH}$ instigates upregulation of catecholamine action leading to lipolysis on adipocytes and enhancement of circulating FA. Elevated supply of FA counteracts THmediated elevated hepatic long-chain FA oxidative process. Elevated circulating FA levels and availability of gluconeogenic substrates from peripheral reserves reciprocates increased gluconeogenesis in T3-treated animals. It has been reported that T3 enhances fasting plasma glucose and free FA levels. Activation of peripheral substrates explains precipitation of hyperglycemia in thyrotoxicosis [84]. Paradoxically, hyperglycemic effect of thyrotoxicosis can be reversed by increased blood supply to muscles providing a better supply of substrate [16]. This phenomenon is shown in Figure 3.

\section{Relation of Antidiabetic Therapy (Metformin) and Risk of Thyroid Related Perturbations}

Cappelli et al. evaluated the thyroid hormone profile by studying the interaction between metformin and circulating thyroid function parameters in patients who were started on metformin [85]. A pilot study on diabetic hypothyroid patient revealed baseline reduction of TSH level after 6 months; similarly a large cohort study on diabetic patients showed significant fall of TSH level in euthyroid patients on L-T4 substitution and subclinical hypothyroid patients who did not receive LT4 treatment, except in euthyroid patients after 1 year on metformin. This study concluded that TSH lowering effect of metformin only seen in untreated hypothyroid patient and with L-T4 replacement therapy irrespective of thyroid function test. Similar findings were reported by Vigersky et al., Cappelli et al., and Chen et al. [86-88].

In vitro studies support the use of metformin in other thyroid diseases other than hypothyroidism. Metformin has inhibited the cell proliferation and growth-stimulatory effect of insulin on thyroid carcinoma cell lines. Same study showed the stimulation of apoptosis and enhancement in the action of chemotherapeutic agents (doxorubicin and cisplatin) by metformin [89]. Other reports support growth inhibitory effect of metformin in mammalian cell lines mediated by mammalian target of Rapamycin (mTOR) and cyclin D1 [90].

\section{Therapeutic Role of Thyroid Hormone Analogues}

Thyroid hormones have profound influence on various physiological processes ranging from metabolism of lipid, protein, and carbohydrate. The literature is punctuated with reports claiming antiatherogenic and lipolytic influences of thyroid hormones. However, their deleterious effects on bone, muscles, and heart are major hurdles [91]. Thyroid hormone analogues have paved the way for the development of novel strategies in the treatment of atherosclerosis, diabetes and obesity [91]. Recent investigations and subsequent findings have provided many cues that could behold trails of complex physiological mechanisms in the endocrine crosstalk of glycaemic surge and thyroid dysfunction [91].

Development of potent thyroid hormone analogues that selectively elude the harmful effects of thyroid hormone, and at the same time, produce desirable therapeutic effects has been the cynosure of scientific research [92-94]. The thrust of the research has been in designing $\mathrm{TH}$ analogues which are devoid of the cardiac complications [27, 95]. Preclinical investigations have demonstrated that carbohydrate response element-binding protein (ChREBP) is the pivotal transcription factor modulating the stimulation of hepatic lipogenesis mediated by glucose. It is the primary target of thyroid hormones in liver and white adipose tissues [66]. ChREBP has been reported to be regulated by TR $\beta$ only and not $\operatorname{TR} \alpha$ in liver and white adipose tissue [66]. 
TABLE 1: Diabetic practice guidelines for thyroid screening in patients with diabetes.

\begin{tabular}{|c|c|c|c|}
\hline Sr. no. & Guidelines & Type 2 diabetes & Comments \\
\hline (1) & $\begin{array}{l}\text { American Thyroid Association guidelines } \\
\text { for detection of thyroid dysfunction [61] }\end{array}$ & $\begin{array}{l}\text { Patients with diabetes may require more } \\
\text { frequent testing }\end{array}$ & $\begin{array}{l}\text { Recommends TSH from } 35 \text { yrs, and every } \\
5 \text { yrs thereafter in all adults; high risk } \\
\text { persons may require more frequent tests } \\
\text { Diabetes mentioned as high-risk but does } \\
\text { not distinguish between T1DM and } \\
\text { T2DM }\end{array}$ \\
\hline (2) & $\begin{array}{l}\text { American Association of Clinical } \\
\text { Endocrinologists, Thyroid disease clinical } \\
\text { Practice guidelines, } 2002 \text { [62] }\end{array}$ & $\begin{array}{l}\text { Thyroid palpation and TSH at diagnosis } \\
\text { and at regular intervals, especially if goitre } \\
\text { or other autoimmune disease presents }\end{array}$ & No specific recommendation for T2DM \\
\hline (3) & $\begin{array}{l}\text { British Thyroid Association and } \\
\text { Association of Clinical Biochemistry } \\
\text { Guidelines, } 2006 \text { [63] }\end{array}$ & $\begin{array}{l}\text { TFT at baseline but routine annual TFT is } \\
\text { not recommended }\end{array}$ & $\begin{array}{l}\text { TSH and antibodies are recommended in } \\
\text { diabetic patients in pregnancy and } \\
\text { postpartum }\end{array}$ \\
\hline
\end{tabular}

\section{Clinical Guidelines Governing the Role of Detection of Thyroid Detection in T2DM Patients}

Various studies have been undertaken to understand the role, importance, and need of determination of thyroid dysfunction in the patients of T2DM. It has been unequivocally apparent that testing for thyroid dysfunction in T2DM patients is necessary and should be carried out annually [13]. Guidelines for screening of thyroid in diabetes patients in UK and USA are presented in Table 1.

The "American Thyroid Association" guidelines for T2DM patients require frequent testing for thyroid dysfunction. They recommend testing from 35 years of age, and every 5 years thereafter in adults. High-risk patients may require more frequent testing. The American Association of Clinical Endocrinologists, Thyroid Disease Clinical Practice Guidelines (2002) recommends thyroid palpation and TSH in diagnosis, especially if goitre or other autoimmune disease presents in association with T2DM. Regular screening for thyroid abnormalities in all diabetic patients will allow early treatment of subclinical thyroid dysfunction. A sensitive serum TSH assay is the screening test of choice. It has also been proposed that in T2DM patients, a TSH assay should be performed at diagnosis and then repeated at least every 5 years.

\section{Conclusion}

In internal medicine, it is repeatedly proven that the association between thyroid dysfunction and diabetes mellitus is evident. Thyroid dysfunction chiefly comprises hypothyroidism and hyperthyroidism although the entity belongs to the same organ but with vast difference in pathophysiology as well as clinical picture. The interface between thyroid malfunction owing to diabetes is a matter of investigation. The literature suggests that polyendocrinal multidysfunction leads to stimulation of a cascade of reactions which are actually antihomeostatic in nature. For instance, hypoadrenalism as well as hypopituitarism exhibits strong linkage with hypothyroidism and consequently diabetes mellitus.
Recent findings have evidenced the intricate bond between subclinical hypothyroidism and diabetes mellitus that deceptively contribute to the major complications such as retinopathy and neuropathy. Cardiovascular events and microor macro-angiopathies are the counterreflection of resurgence of heavily disturbed lipid metabolism due to thyroid dyscrasias. It is also evident from the existing literature that insulin resistance bears an indispensable role in connecting T2DM and thyroid dysfunction. Novel molecules have shown the path for the development of suitable thyroid hormone receptor analogues to treat metabolic diseases. It is important to diagnose thyroid dysfunction in T2DM patients, and this practice should be inculcated in clinical settings with immediate effect to nourish further understanding of thyroid dysfunction and T2DM.

\section{Conflict of Interests}

The author declares that he has no conflict of interests.

\section{Authors' Contributions}

The main author contributed fully to the review.

\section{Acknowledgment}

The author would like to thank BioQuest Solutions for providing editorial services for this review.

\section{References}

[1] F. A. Coller and C. B. Huggins, "Effect of hyperthyroidism upon diabetes mellitus: striking improvement in diabetes mellitus from thyroidectomy," Annals of Surgery, vol. 86, no. 6, pp. 877884, 1927.

[2] G. Brenta, S. Danzi, and I. Klein, "Potential therapeutic applications of thyroid hormone analogs," Nature Clinical Practice Endocrinology and Metabolism, vol. 3, no. 9, pp. 632-640, 2007.

[3] F. Goglia, M. Moreno, and A. Lanni, "Action of thyroid hormones at the cellular level: the mitochondrial target," FEBS Letters, vol. 452, no. 3, pp. 115-120, 1999. 
[4] R. Kadiyala, R. Peter, and O. E. Okosieme, "Thyroid dysfunction in patients with diabetes: clinical implications and screening strategies," International Journal of Clinical Practice, vol. 64, no. 8, pp. 1130-1139, 2010.

[5] O. Kordonouri, A. M. Maguire, M. Knip et al., "Other complications and associated conditions with diabetes in children and adolescents," Pediatric Diabetes, vol. 10, no. 12, pp. 204-210, 2009.

[6] R. W. Holl, B. Böhm, U. Loos, M. Grabert, E. Heinze, and J. Homoki, "Thyroid autoimmunity in children and adolescents with type 1 diabetes mellitus. Effect of age, gender and HLA type," Hormone Research, vol. 52, no. 3, pp. 113-118, 1999.

[7] J. M. Barker, J. Yu, L. Yu et al., "Autoantibody "subspecificity" in type 1 diabetes: risk for organ-specific autoimmunity clusters in distinct groups," Diabetes Care, vol. 28, no. 4, pp. 850-855, 2005.

[8] J. E. Donckier, "Endocrine diseases and diabetes," in Text Book of Diabetes Mellitus, J. C. Pickup and G. Williams, Eds., vol. 27, pp. 21-27, Blackwell Publishing Company, Chichester, UK, 2003.

[9] J. D. Baxter, W. H. Dillmann, B. L. West et al., "Selective modulation of thyroid hormone receptor action," Journal of Steroid Biochemistry and Molecular Biology, vol. 76, no. 1-5, pp. 31-42, 2001.

[10] J. D. Baxter and P. Webb, "Thyroid hormone mimetics: potential applications in atherosclerosis, obesity and type 2 diabetes," Nature Reviews Drug Discovery, vol. 8, no. 4, pp. 308-320, 2009.

[11] W. M. G. Tunbridge, D. C. Evered, and R. Hall, "The spectrum of thyroid disease in a community: the Whickham survey," Clinical Endocrinology, vol. 7, no. 6, pp. 481-493, 1977.

[12] J. G. Hollowell, N. W. Staehling, W. D. Flanders et al., "Serum TSH, T4, and thyroid antibodies in the United States population (1988 to 1994): National Health and Nutrition Examination Survey (NHANES III)," Journal of Clinical Endocrinology and Metabolism, vol. 87, no. 2, pp. 489-499, 2002.

[13] P. Perros, R. J. McCrimmon, G. Shaw, and B. M. Frier, "Frequency of thyroid dysfunction in diabetic patients: value of annual screening," Diabetic Medicine, vol. 12, no. 7, pp. 622-627, 1995.

[14] D. H. Akbar, M. M. Ahmed, and J. Al-Mughales, "Thyroid dysfunction and thyroid autoimmunity in Saudi type 2 diabetics," Acta Diabetologica, vol. 43, no. 1, pp. 14-18, 2006.

[15] S. Stanická, K. Vondra, T. Pelikánová, P. Vlček, M. Hill, and V. Zamrazil, "Insulin sensitivity and counter-regulatory hormones in hypothyroidism and during thyroid hormone replacement therapy," Clinical Chemistry and Laboratory Medicine, vol. 43, no. 7, pp. 715-720, 2005.

[16] P. Mitrou, S. A. Raptis, and G. Dimitriadis, "Insulin action in hyperthyroidism: a focus on muscle and adipose tissue," Endocrine Reviews, vol. 31, no. 5, pp. 663-679, 2010.

[17] V. Lambadiari, P. Mitrou, E. Maratou et al., "Thyroid hormones are positively associated with insulin resistance early in the development of type 2 diabetes," Endocrine, vol. 39, no. 1, pp. 28-32, 2011.

[18] M. Potenza, M. A. Via, and R. T. Yanagisawa, "Excess thyroid hormone and carbohydrate metabolism," Endocrine Practice, vol. 15, no. 3, pp. 254-262, 2009.

[19] M. S. Eledrisi, M. S. Alshanti, M. F. Shah, B. Brolosy, and N. Jaha, "Overview of the diagnosis and management of diabetic ketoacidosis," American Journal of the Medical Sciences, vol. 331, no. 5, pp. 243-251, 2006.

[20] T. L. Althausen and M. Stockholm, "The influence of the thyroid gland on absorption in the digestive tract," The American Journal of Physiology, vol. 123, no. 3, pp. 577-588, 1938.
[21] L. H. Duntas, J. Orgiazzi, and G. Brabant, "The interface between thyroid and diabetes mellitus," Clinical Endocrinology, vol. 75, no. 1, pp. 1-9, 2011.

[22] A. Clark, L. C. Jones, E. de Koning, B. C. Hansen, and D. R. Matthews, "Decreased insulin secretion in type 2 diabetes: a problem of cellular mass or function?” Diabetes, vol. 50, no. 1, pp. S169-S171, 2001.

[23] J. P. Randin, B. Scazziga, E. Jequier, and J. P. Felber, "Study of glucose and lipid metabolism by continuous indirect calorimetry in Graves' disease: effect of an oral glucose load," Journal of Clinical Endocrinology and Metabolism, vol. 61, no. 6, pp. 11651171, 1985.

[24] R. A. DeFronzo, "Pathogenesis of type 2 diabetes mellitus," Medical Clinics of North America, vol. 88, no. 4, pp. 787-835, 2004.

[25] D. M. Muoio and C. B. Newgard, "Mechanisms of disease: molecular and metabolic mechanisms of insulin resistance and $\beta$-cell failure in type 2 diabetes," Nature Reviews Molecular Cell Biology, vol. 9, no. 3, pp. 193-205, 2008.

[26] G. Dimitriadis, P. Mitrou, V. Lambadiari et al., "Insulin-stimulated rates of glucose uptake in muscle in hyperthyroidism: the importance of blood flow," Journal of Clinical Endocrinology and Metabolism, vol. 93, no. 6, pp. 2413-2415, 2008.

[27] G. Brenta, F. S. Celi, M. Pisarev, M. Schnitman, I. Sinay, and P. Arias, "Acute thyroid hormone withdrawal in athyreotic patients results in a state of insulin resistance." Thyroid, vol. 19, no. 6, pp. 665-669, 2009.

[28] R. A. DeFronzo, R. Gunnarsson, and O. Bjorkman, "Effects of insulin on peripheral and splanchnic glucose metabolism in noninsulin-dependent (type II) diabetes mellitus," Journal of Clinical Investigation, vol. 76, no. 1, pp. 149-155, 1985.

[29] R. A. DeFronzo, "Pathogenesis of type 2 diabetes: metabolic and molecular implications for identifying diabetes genes," Diabetes Reviews, vol. 5, no. 3, pp. 177-269, 1997.

[30] A. Mari, J. Wahren, R. A. DeFronzo, and E. Ferrannini, “Glucose absorption and production following oral glucose: comparison of compartmental and arteriovenous-difference methods," Metabolism: Clinical and Experimental, vol. 43, no. 11, pp. 1419$1425,1994$.

[31] L. Mandarino, R. Bonadonna, O. McGuinness, and D. Wasserman, "Regulation of muscle glucose uptake in vivo," in Handbook of Physiology, The Endocrine System, The Endocrine Pancreas and Regulation of Metabolism, L. S. Jefferson and A. D. Cherrington, Eds., vol. 2, pp. 803-848, Oxford University Press, Oxford, UK, 2001.

[32] K. B. Kapadia, P. A. Bhatt, and J. S. Shah, "Association between altered thyroid state and insulin resistance," Journal of Pharmacology and Pharmacotherapeutics, vol. 3, pp. 156-160, 2012.

[33] G. Chen, J. Wu, Y. Lin et al., "Associations between cardiovascular risk, insulin resistance, $\beta$-cell function and thyroid dysfunction: a cross-sectional study in She ethnic minority group of Fujian Province in China," European Journal of Endocrinology, vol. 163, no. 5, pp. 775-782, 2010.

[34] G. D. Dimitriadis and S. A. Raptis, "Thyroid hormone excess and glucose intolerance," Experimental and Clinical Endocrinology and Diabetes, vol. 109, no. 2, pp. S225-S239, 2001.

[35] M. Beylot, J. P. Riou, F. Bienvenu, and R. Mornex, "Increased ketonaemia in hyperthyroidism. Evidence for a $\beta$-adrenergic mechanism," Diabetologia, vol. 19, no. 6, pp. 505-510, 1980.

[36] M. Beylot, "Regulation of in vivo ketogenesis: role of free fatty acids and control by epinephrine, thyroid hormones, insulin 
and glucagon," Diabetes and Metabolism, vol. 22, no. 5, pp. 299304, 1996.

[37] J. Rezzonico, H. Niepomniszcze, M. Rezzonico, E. Pusiol, M. Alberto, and G. Brenta, "The association of insulin resistance with subclinical thyrotoxicosis," Thyroid, vol. 21, no. 9, pp. 945949, 2011.

[38] M. Peppa, G. Betsi, and G. Dimitriadis, "Lipid abnormalities and cardiometabolic risk in patients with overt and subclinical thyroid disease," Journal of Lipids, vol. 2011, Article ID 575840, 9 pages, 2011.

[39] C. C. Wang and J. E. B. Reusch, "Diabetes and cardiovascular disease: changing the focus from glycemic control to improving long-term survival," The American Journal of Cardiology, vol. 110, no. 9, pp. 58B-68B, 2012.

[40] P. Cavallo-Perin, A. Bruno, L. Boine, M. Cassader, G. Lenti, and G. Pagano, "Insulin resistance in Graves' disease: a quantitative in-vivo evaluation," European Journal of Clinical Investigation, vol. 18, no. 6, pp. 607-613, 1988.

[41] L. P. Klieverik, C. P. Coomans, E. Endert et al., "Thyroid hormone effects on whole-body energy homeostasis and tissuespecific fatty acid uptake in vivo," Endocrinology, vol. 150, no. 12, pp. 5639-5648, 2009.

[42] S. P. Weinstein, E. O’Boyle, M. Fisher, and R. S. Haber, "Regulation of GLUT2 glucose transporter expression in liver by thyroid hormone: evidence for hormonal regulation of the hepatic glucose transport system," Endocrinology, vol. 135, no. 2, pp. 649-654, 1994.

[43] T. Mokuno, K. Uchimura, R. Hayashi et al., "Glucose transporter 2 concentrations in hyper- and hypothyroid rat livers," Journal of Endocrinology, vol. 160, no. 2, pp. 285-289, 1999.

[44] G. Dimitriadis, B. Baker, H. Marsh et al., "Effect of thyroid hormone excess on action, secretion, and metabolism of insulin in humans.", The American Journal of Physiology, vol. 248, no. 5, pp. E593-601, 1985.

[45] A. J. McCulloch, D. G. Johnston, and P. H. Baylis, "Evidence that thyroid hormones regulate gluconeogenesis from glycerol in man," Clinical Endocrinology, vol. 19, no. 1, pp. 67-76, 1983.

[46] M. C. Foss, G. M. G. F. Paccola, M. J. A. Saad, W. P. Pimenta, C. E. Piccinato, and N. Iazigi, "Peripheral glucose metabolism in human hyperthyroidism," Journal of Clinical Endocrinology and Metabolism, vol. 70, no. 4, pp. 1167-1172, 1990.

[47] D. C. Shen, M. B. Davidson, S. W. Kuo, and W. H. Sheu, "Peripheral and hepatic insulin antagonism in hyperthyroidism," Journal of Clinical Endocrinology and Metabolism, vol. 66, no. 3, pp. 565-569, 1988.

[48] M. Haluzik, J. Nedvidkova, V. Bartak et al., "Effects of hypo and hyperthyroidism on noradrenergic activity and glycerol concentrations in human subcutaneous abdominal adipose tissue assessed with microdialysis," Journal of Clinical Endocrinology and Metabolism, vol. 88, no. 12, pp. 5605-5608, 2003.

[49] G. Mory, D. Ricquier, P. Pesquies, and P. Hemon, "Effects of hypothyroidism on the brown adipose tissue of adult rats: comparison with the effects of adaptation to cold," Journal of Endocrinology, vol. 91, no. 3, pp. 515-524, 1981.

[50] H. C. Freake and J. H. Oppenheimer, "Stimulation and S14 mRNAand lipogenesis in brown fat by hypothyroidism, cold exposure, and cafeteria feeding: evidence supporting a general role for S14 in lipogenesis and lipogenesis in the maintenance of thermogenesis," Proceedings of the National Academy of Sciences of the United States of America, vol. 84, no. 9, pp. 3070-3074, 1987.
[51] G. Dimitriadis, M. Parry-Billings, S. Bevan et al., "The effects of insulin on transport and metabolism of glucose in skeletal muscle from hyperthyroid and hypothyroid rats," European Journal of Clinical Investigation, vol. 27, no. 6, pp. 475-483, 1997.

[52] A. Dubaniewicz, H. Kaciuba-Uscilko, K. Nazar, and L. Budohoski, "Sensitivity of the soleus muscle to insulin in resting and exercising rats with experimental hypo- and hyper-thyroidism," Biochemical Journal, vol. 263, no. 1, pp. 243-247, 1989.

[53] P. Cettour-Rose, C. Theander-Carrillo, C. Asensio et al., "Hypothyroidism in rats decreases peripheral glucose utilisation, a defect partially corrected by central leptin infusion," Diabetologia, vol. 48, no. 4, pp. 624-633, 2005.

[54] C. Rochon, I. Tauveron, C. Dejax et al., "Response of glucose disposal to hyperinsulinaemia in human hypothyroidism and hyperthyroidism," Clinical Science, vol. 104, no. 1, pp. 7-15, 2003.

[55] A. Handisurya, G. Pacini, A. Tura, A. Gessl, and A. KautzkyWiller, "Effects of T4 replacement therapy on glucose metabolism in subjects with subclinical (SH) and overt hypothyroidism (OH)," Clinical Endocrinology, vol. 69, no. 6, pp. 963-969, 2008.

[56] G. Dimitriadis, P. Mitrou, V. Lambadiari et al., "Insulin action in adipose tissue and muscle in hypothyroidism," Journal of Clinical Endocrinology and Metabolism, vol. 91, no. 12, pp. 49304937, 2006.

[57] E. Maratou, D. J. Hadjidakis, M. Peppa et al., "Studies of insulin resistance in patients with clinical and subclinical hyperthyroidism," European Journal of Endocrinology, vol. 163, no. 4, pp. 625630, 2010.

[58] P. H. Dessein, B. I. Joffe, and A. E. Stanwix, "Subclinical hypothyroidism is associated with insulin resistance in rheumatoid arthritis," Thyroid, vol. 14, no. 6, pp. 443-446, 2004.

[59] M. Owecki, E. Nikisch, and J. Sowiński, "Hypothyroidism has no impact on insulin sensitivity assessed with HOMA-IR in totally thyroidectomized patients," Acta Clinica Belgica, vol. 61, no. 2, pp. 69-73, 2006.

[60] P. E. Harris, M. Walker, F. Clark, P. D. Home, and K. G. M. M. Alberti, "Forearm muscle metabolism in primary hypothyroidism," European Journal of Clinical Investigation, vol. 23, no. 9, pp. 585-588, 1993.

[61] P. W. Ladenson, P. A. Singer, K. B. Ain et al., "American thyroid association guidelines for detection of thyroid dysfunction," Archives of Internal Medicine, vol. 160, no. 11, pp. 1573-1575, 2000.

[62] H. J. Baskin, R. H. Cobin, D. S. Duick et al., "American Association of Clinical Endocrinologists medical guidelines for clinical practice for the evaluation and treatment of hyperthyroidism and hypothyroidism," Endocrine Practice, vol. 8, no. 6, pp. 457469, 2002.

[63] "UK guidelines for the use of thyroid function tests," 2006, http://www.british-thyroid-association.org/info-for-patients/ Docs/TFT_guideline_final_version_July_2006.pdf.

[64] S. P. Weinstein, E. O’Boyle, and R. S. Haber, "Thyroid hormone increases basal and insulin-stimulated glucose transport in skeletal muscle: the role of GLUT4 glucose transporter expression," Diabetes, vol. 43, no. 10, pp. 1185-1189, 1994.

[65] C. N. Mariash, C. H. McSwigan, and H. C. Towle, "Glucose and triiodothyronine both induce malic enzyme in the rat hepatocyte culture: evidence that triiodothyronine multiplies a primary glucose-generated signal," Journal of Clinical Investigation, vol. 68, no. 6, pp. 1485-1490, 1981.

[66] K. Gauthier, C. Billon, M. Bissler et al., "Thyroid hormone receptor $\beta(\mathrm{TR} \beta)$ and liver $\mathrm{X}$ receptor (LXR) regulate carbohydrate-response element-binding protein (ChREBP) expression 
in a tissue-selective manner," Journal of Biological Chemistry, vol. 285, no. 36, pp. 28156-28163, 2010.

[67] W. Becker, R. Kluge, T. Kantner et al., "Differential hepatic gene expression in a polygenic mouse model with insulin resistance and hyperglycemia: evidence for a combined transcriptional dysregulation of gluconeogenesis and fatty acid synthesis," Journal of Molecular Endocrinology, vol. 32, no. 1, pp. 195-208, 2004.

[68] G. Brenta, "Diabetes and thyroid disorders," British Journal of Diabetes and Vascular Disease, vol. 10, no. 4, pp. 172-177, 2010.

[69] N. Viguerie, L. Millet, S. Avizou, H. Vidal, D. Larrouy, and D. Langin, "Regulation of human adipocyte gene expression by thyroid hormone," Journal of Clinical Endocrinology and Metabolism, vol. 87, no. 2, pp. 630-634, 2002.

[70] L. C. Moeller, A. M. Dumitrescu, R. L. Walker, P. S. Meltzer, and S. Refetoff, "Thyroid hormone responsive genes in cultured human fibroblasts," Journal of Clinical Endocrinology and Metabolism, vol. 90, no. 2, pp. 936-943, 2005.

[71] J. M. Weitzel, C. Radtke, and H. J. Seitz, "Two thyroid hormonemediated gene expression patterns in vivo identified by cDNA expression arrays in rat," Nucleic Acids Research, vol. 29, no. 24, pp. 5148-5155, 2001.

[72] P. de Lange, A. Feola, M. Ragni et al., "Differential 3,5,3' triiodothyronine-mediated regulation of uncoupling protein 3 transcription: role of fatty acids," Endocrinology, vol. 148, no. 8, pp. 4064-4072, 2007.

[73] R. Senese, V. Valli, M. Moreno et al., "Uncoupling protein 3 expression levels influence insulin sensitivity, fatty acid oxidation, and related signaling pathways," Pflugers Archiv: European Journal of Physiology, vol. 461, no. 1, pp. 153-164, 2011.

[74] M. Moreno, E. Silvestri, R. de Matteis et al., "3, 5-Diiodo-Lthyronine prevents high-fat-diet-induced insulin resistance in rat skeletal muscle through metabolic and structural adaptations," The FASEB Journal, vol. 25, no. 10, pp. 3312-3324, 2011.

[75] Y. Tomer and F. Menconi, "Type 1 diabetes and autoimmune thyroiditis: the genetic connection," Thyroid, vol. 19, no. 2, pp. 99-102, 2009.

[76] F. Menconi, R. Osman, M. C. Monti, D. A. Greenberg, E. S. Concepcion, and Y. Tomer, "Shared molecular amino acid signature in the HLA-DR peptide binding pocket predisposes to both autoimmune diabetes and thyroiditis," Proceedings of the National Academy of Sciences of the United States of America, vol. 107, no. 39, pp. 16899-16903, 2010.

[77] P. M. Yen, "Physiological and molecular basis of Thyroid hormone action," Physiological Reviews, vol. 81, no. 3, pp. 1097$1142,2001$.

[78] A. Boelen, "Thyroid hormones and glucose metabolism: the story begins before birth," Experimental Physiology, vol. 94, no. 10, pp. 1050-1051, 2009.

[79] L. P. Klieverik, S. F. Janssen, A. Van Riel et al., "Thyroid hormone modulates glucose production via a sympathetic pathway from the hypothalamic paraventricular nucleus to the liver," Proceedings of the National Academy of Sciences of the United States of America, vol. 106, no. 14, pp. 5966-5971, 2009.

[80] J. M. Dora, W. E. Machado, J. Rheinheimer, D. Crispim, and A. L. Maia, "Association of the type 2 deiodinase Thr92Ala polymorphism with type 2 diabetes: case-control study and meta-analysis," European Journal of Endocrinology, vol. 163, no. 3, pp. 427-434, 2010.

[81] A. Chidakel, D. Mentuccia, and F. S. Celi, "Peripheral metabolism of thyroid hormone and glucose homeostasis," Thyroid, vol. 15, no. 8, pp. 899-903, 2005.
[82] E. Maratou, D. J. Hadjidakis, A. Kollias et al., "Studies of insulin resistance in patients with clinical and subclinical hypothyroidism," European Journal of Endocrinology, vol. 160, no. 5, pp. 785-790, 2009.

[83] J. A. Chavez and S. A. Summers, "Lipid oversupply, selective insulin resistance, and lipotoxicity: molecular mechanisms," Biochimica et Biophysica Acta, vol. 1801, no. 3, pp. 252-265, 2010.

[84] M. D. Erion, E. E. Cable, B. R. Ito et al., "Targeting thyroid hormone receptor- $\beta$ agonists to the liver reduces cholesterol and triglycerides and improves the therapeutic index," Proceedings of the National Academy of Sciences of the United States of America, vol. 104, no. 39, pp. 15490-15495, 2007.

[85] C. Cappelli, M. Rotondi, I. Pirola et al., “TSH-lowering effect of metformin in type 2 diabetic patients: differences between euthyroid, untreated hypothyroid, and euthyroid on L-T4 therapy patients," Diabetes Care, vol. 32, no. 9, pp. 1589-1590, 2009.

[86] R. A. Vigersky, A. Filmore-Nassar, and A. R. Glass, "Thyrotropin suppression by metformin," The Journal of Clinical Endocrinology \& Metabolism, vol. 91, no. 1, pp. 225-227, 2006.

[87] C. Cappelli, M. Rotondi, I. Pirola et al., "Thyreotropin levels in diabetic patients on metformin treatment," European Journal of Endocrinology, vol. 167, no. 2, pp. 261-265, 2012.

[88] G. Chen, S. Xu, K. Renko, and M. Derwahl, "Metformin inhibits growth of thyroid carcinoma cells, suppresses selfrenewal of derived cancer stem cells, and potentiates the effect of chemotherapeutic agents," Journal of Clinical Endocrinology \& Metabolism, vol. 97, no. 4, pp. E510-E520, 2012.

[89] J. Klubo-Gwiezdzinska, K. Jensen, J. Costello et al., "Metformin inhibits growth and decreases resistance to anoikis in medullary thyroid cancer cells," Endocrine-Related Cancer, vol. 19, no. 3, pp. 447-456, 2012.

[90] J. D. Baxter and P. Webb, "Thyroid hormone mimetics: potential applications in atherosclerosis, obesity and type 2 diabetes," Nature Reviews Drug Discovery, vol. 8, no. 4, pp. 308-320, 2009.

[91] P. Webb, "Selective activators of thyroid hormone receptors," Expert Opinion on Investigational Drugs, vol. 13, no. 5, pp. 489500, 2004.

[92] M. Moreno, P. de Lange, A. Lombardi, E. Silvestri, A. Lanni, and F. Goglia, "Metabolic effects of thyroid hormone derivatives," Thyroid, vol. 18, no. 2, pp. 239-253, 2008.

[93] H. A. Yoshihara and T. S. Scanlan, "Selective thyroid hormone receptor modulators.", Current Topics in Medicinal Chemistry, vol. 3, no. 14, pp. 1601-1616, 2003.

[94] G. Brenta, S. Danzi, and I. Klein, "Potential therapeutic applications of thyroid hormone analogs," Nature Clinical Practice Endocrinology and Metabolism, vol. 3, no. 9, pp. 632-640, 2007.

[95] M. F. Celani, M. E. Bonati, and N. Stucci, "Prevalence of abnormal thyrotropin concentrations measured by a sensitive assay in patients with type 2 diabetes mellitus." Diabetes Research, vol. 27, no. 1, pp. 15-25, 1994. 


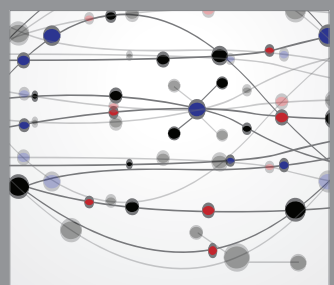

The Scientific World Journal
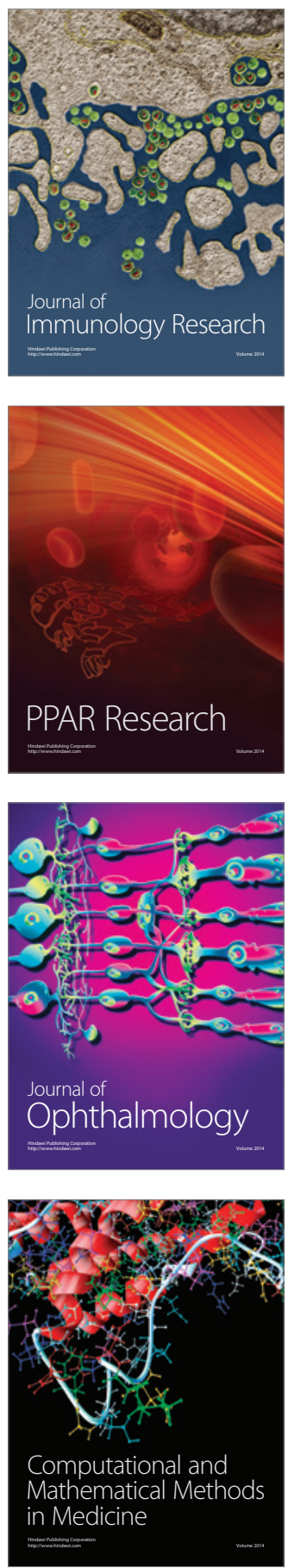

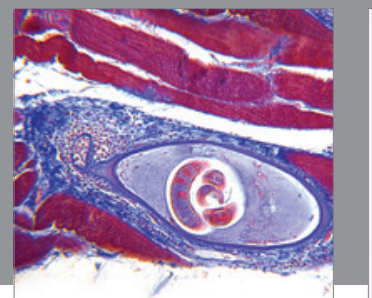

Gastroenterology

Research and Practice
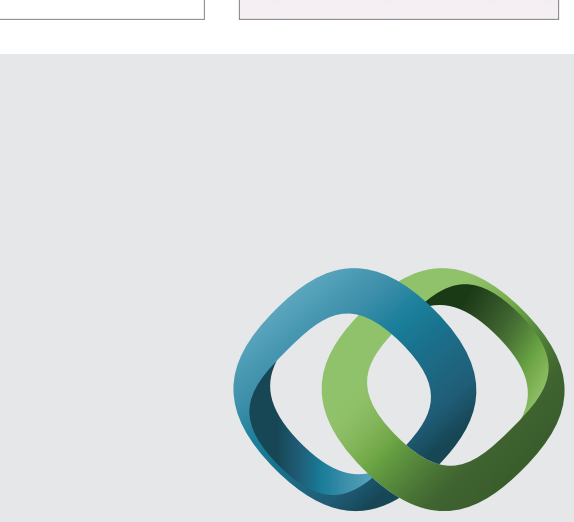

\section{Hindawi}

Submit your manuscripts at

http://www.hindawi.com
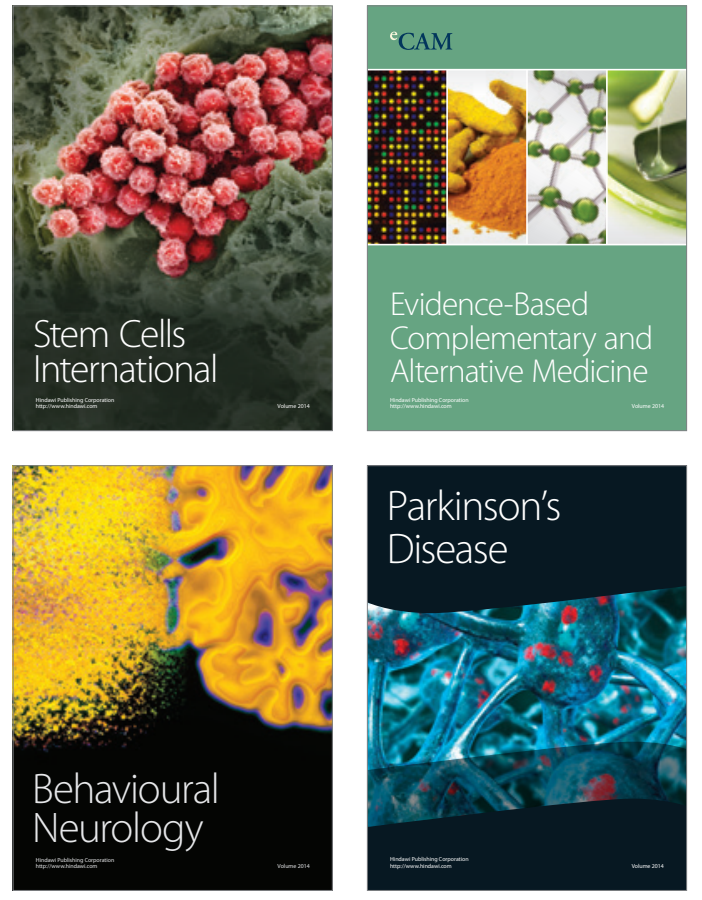
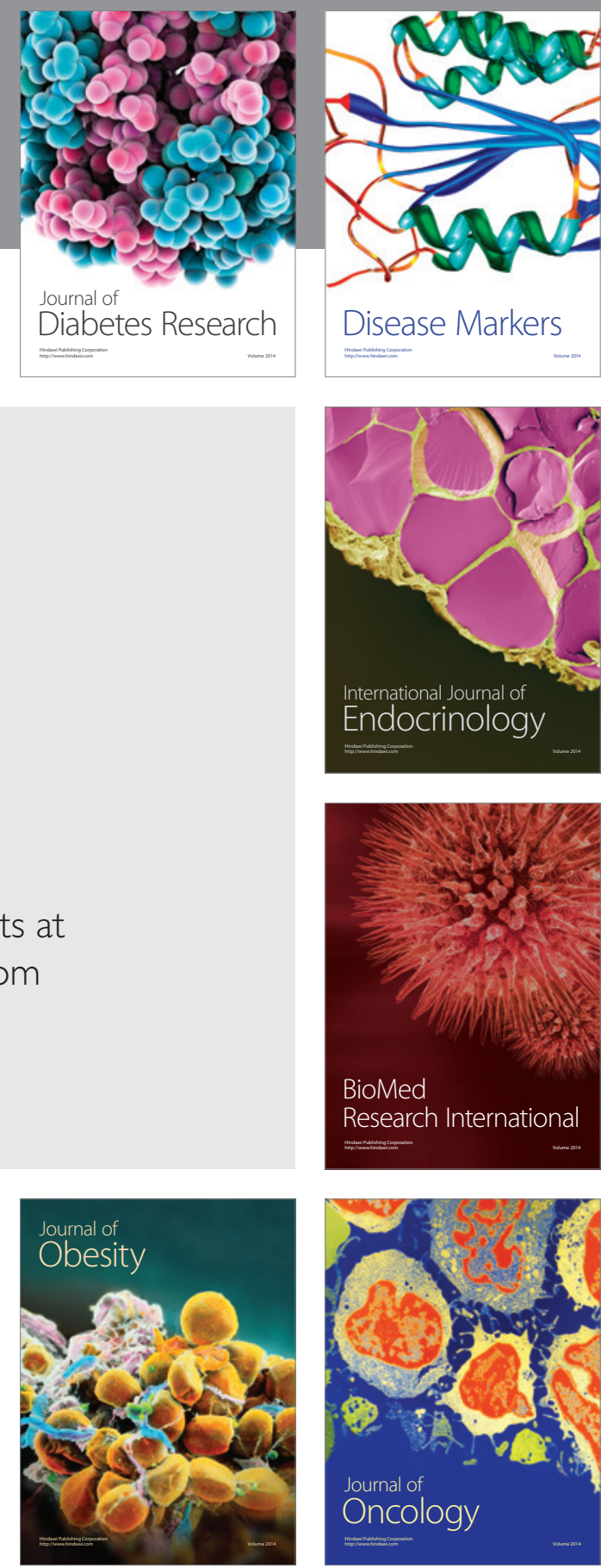

Disease Markers
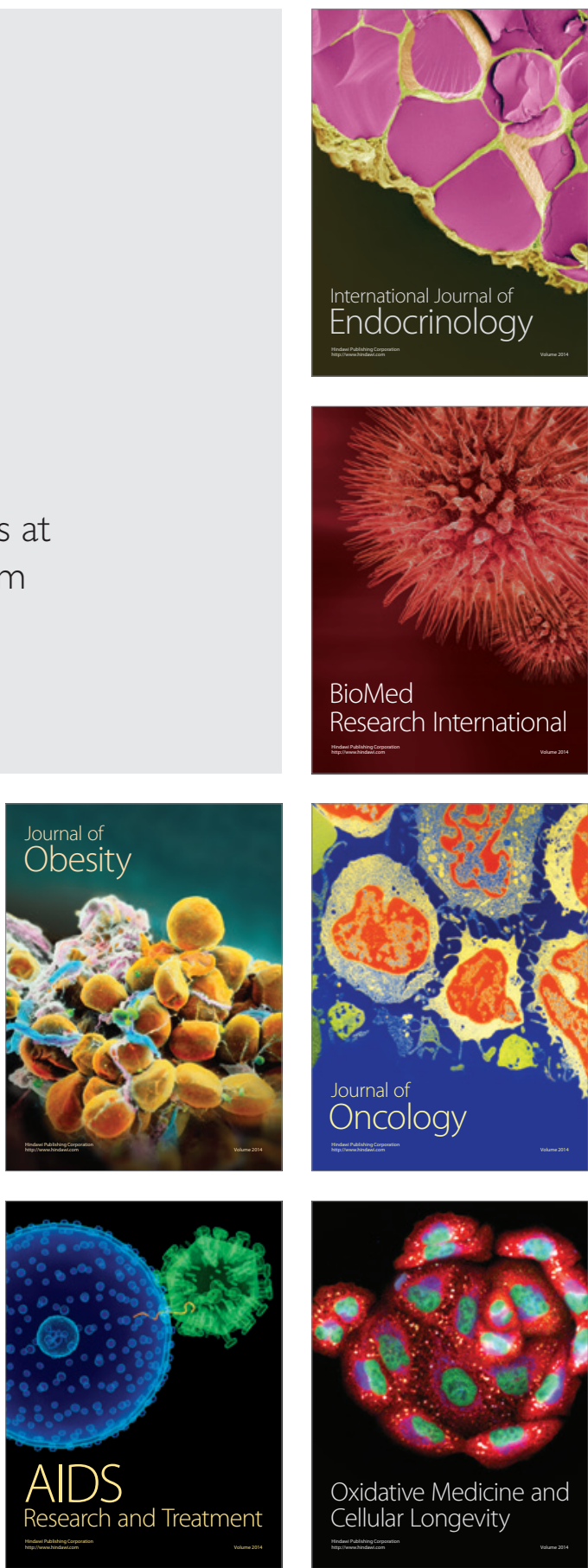